\title{
Consideration of Real Fire Conditions While Calculating the Critical Fire Load Density in Compartments on the Basis of the Kinetic Approach
}

\author{
VLADIMIR M. ROITMAN \\ Moscow State University of Civil Engineering \\ 26. Yaroslavskoye shosse, Moscow, 129337, Russia
}

\section{ABSTRACT}

This paper presents the theoretical background and an engineering calculation method for the determination of the maximum (critical) value of the fire load density for which a failure does not occur for the load bearing structures in a defined fire compartment when exposed to a simulated natural fire. The critical fire load density is suggested to be defined for real fire exposure on the structure on the basis of a kinetic approach. The use of the kinetic approach to solve this problem as well makes it possible to consider more precisely the real fire behaviour of the structure than when calculating on the basis of a static approach.

KEYWORDS: real fire, fire load, compartment, temperature state, load bearing capacity, structure.

\section{INTRODUCTION}

Under the real fire the structural fire behaviour depends greatly upon the value of the fire load density in a compartment. That is why, the structural fire behaviour of the building under the real fire exposure can be provided by limiting the fire load density in a compartment $/ 6 /$.

In this connection the important problem of fire safety is the obtaining of the data concerning the maximum values of the fire load density in a compartment for which a failure does not occur for the load bearing structures in a defined fire compartment when exposed to a simulated natural fire.

The maximum value of the fire load density in a compartment for which a failure does not occur for the load bearing structures in a defined fire compartment when exposed to a simulated natural fire is proposed /1/ to be called "critical".

In papers $/ 2-6 /$ the use of static and kinetic approaches when calculating the structural fire behaviour for a real fire exposure was analyzed.

The static aproach means that static system of the bounded 
atoms of a solid body interacts with an external force. In the limits of this conception the material resistance depends on the correlation between the cohesion forces and external forces, influencing interatomic bonds $/ 5 /$.

The introduction in static (mechanical) approach of the conception of "ultimate strength" and "limit temperature" of heating of the material reflects the critical nature of breaking the stability of such static system under heating with simultaneous action of external forces.

The corresponding change of structural strength under the conditions of high temperature heating is expressed $/ 1 /$ as the function "strength -temperature" independent on time:

$R=f(T)$

or in the dimensionless values as follows:

$m(T)=\frac{R(T)}{R}=f(T)$

where $R$ is the structural strength found by means of the standard mechanical tests under normal conditions, $R(T)$ - the structural strength found by means of mechanical tests under the definite regime of heating.

The new opportunities of the development of the material strength and durability arise in connection with the appearance of the kinetic conception of the physical nature of strength and the destruction of solid bodies $/ 5 /$. According to this conception the destruction is regarded as the real proressing in time process of the accumulation of damages and the durability of objects characterizes the period of their existence from the moment of applying the force till the moment of their destruction.

In the theory of fire resistance time is one of the principal characteristics of behaviour of building materials and structures under the conditions of fire exposure. The conception of "fire resistance limit" is equivalent to the conception of the durability of solid bodies referring to the specific conditions of fire. In reality "fire resistance limit" of building structures characterizes the "period of its existence from the moment of the fire appearance to the moment of arising its critical state /5/ that is "durability" under the conditions of fire.

In this paper, the use of a kinetic aproach for the calculation of the critical fire load density in a defined compartment based directly on a real fire exposure on structure is shown.

\section{PHYSICAL MODEL}

For a load bearing structure, the design criterion for an analytical determination of the critical fire load density in a compartment, based directly on a real fire exposure on the 
structural elements, implies that the fire load density $q$ will be criticalq ${ }^{\mathrm{cr}}$, when the minimum value of the load bearing capacity min $R(\tau, q)$ during the real fire exposure meets the load effect on the structure $S$,i.e.:

$\min \{R(\tau, q)\}=s$, then $q=q^{c r}$

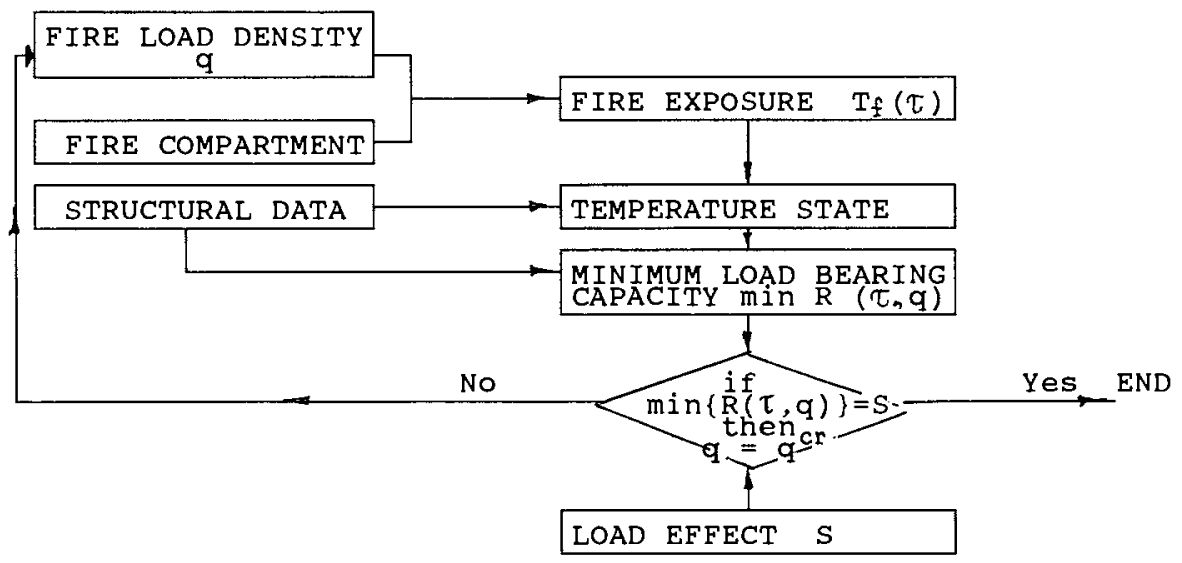

FIGURE 1.Physical model for an analytical engineering design of the critical fire load density in a compartment, based directly on a real fire exposure

The physical model for a structural fire engineering design is shown summarily in Fig. 1 .

The procedure can be subdivided into the following main steps (Fig.1):prediction of the compartment fire temperature -time curve on the basis of the fire load density and the fire compartment characteristics, the temperature-time fields in the structure, the load bearing capacity of the structure and a comparison between the minimum value of the load bearing capacity during the relevant fire process and the load effect $S$, according to equation ( 3 ).

To solve the problem of the determinaton of the critical fire load density of a given compartment is enough to test the design criteria (3) for the weakest structure in the compartment.Usually, such structures are the bending ones (slabs, beams, etc.).

For a reinforced concrete slab, the ultimate fire behaviour is defined by the deformation of the principal tensile reinforcement, the design criterion (3) based on the kinetic approach can be shown to be:

$\max \{\varepsilon(\tau, q)\}=\varepsilon^{c r}$, then $q=q^{c r}$

where: $\mathcal{E}(\tau, q$ ) - the change of a complete slab principal 
reinforcement deformation depending upon the time of the real fire exposure and the fire load density in a compartment $q$; $\varepsilon^{\mathrm{cr}}$ - critical value of the complete principal reinforcement deformation when time of failure under the fire takes place.

On the basis of the static approach design criterion (3) has the following form /1/:

$\max \left\{T_{S}(\tau, q)\right\}=T_{S}^{c r}$, then $q=q^{c r}$

where: TS $(\tau, q)$ - the temperature change of the slab principal reinforcement depending on time of real fire exposure, regime of which under other equal conditions is defined by the fire load density value in a compartment : $T_{S}^{c r}$ - the critical value of heating temperature of the slab reinforcement under fire when the time of failure has come.

CALCULATION METHOD

For an analytical determination of the critical fire load density in a compartment based on the physical model / in Fig.1/, one can use calculation methods described in $/ 5,6 /$.

For the first step of calculation - the determination of the gas temperature in the compartment $T_{f}(\tau)$ at time (min) of fire exposure the following equations can be used:

when $\tau \leqslant \tau_{m} \quad T_{f}(\tau)=\Psi 345 \log (8 \tau+1)+T_{0}$

when $\tau>\tau_{m} \quad T_{f}(\tau)=\Psi 345 \log (8 \tau+1)-V_{c}\left(\tau-\tau_{m}\right)+T_{0}$

where $T_{0}$ - gas temperature of compartment at $\tau=0,{ }^{\circ} \mathrm{C} \Phi^{\mathrm{T}}-$ coefficient of fire intensity, which expresses the ratio of gas temperature in compartment at any time of fire exposure to the temperature of the standard fire at the same $t i m e ; \tau_{m}{ }^{-}$the time to reach the maximum gas temperature in the compartment $\mathrm{T}_{\mathrm{f}}^{\max }$, min, in the real fire exposure; $V_{c}-$ a parameter which characterizes the descending rate of the gas temperature in the compartment, ${ }^{\circ} \mathrm{C} / \mathrm{min}$.

Approximately, the folliwing equations apply for $\Psi, \tau_{m}$, and $V_{c}$ /5,6/

$$
\begin{aligned}
& \Psi=1.37-\frac{150 \mathrm{~K}_{1, \text { red }}-0,65}{\left(\mathrm{~K}_{1, \mathrm{red}}\right)^{2} 10000} \\
& \tau_{m}=\frac{60 \mathrm{qred}_{\mathrm{red}}}{8318 \mathrm{~K}_{1, \mathrm{red}}-4021\left(\mathrm{~K}_{1, \mathrm{red}}\right)^{2}} \\
& V_{c}=\frac{98000 \mathrm{~K}_{1, \mathrm{red}}-1500}{\mathrm{q}_{\mathrm{red}}}
\end{aligned}
$$

where $K_{1}$,red- equivalent opening factor, $\mathrm{m}^{1 / 2} / 2,4,6 /$;

$q_{\text {red }}$ - equivalent fire load density of the enclosures of the compartment, $M J / \mathrm{m}^{2} / 2,4,6 /$. 
The theoretical methods for the second step of calculation are described in paper $/ 5,6 /$. They give the opportunity to solve, in a simple way, the thermophysical fire behaviour of structures with the consideration of real fire conditions on the basis of the principle of superposition.

The method of superposition allows the solution of a complex task to be broken down into several tasks which are less complicated. In this case, the two basic phases of the real fire exposure described by the compartment gas temperature (the heating phase and the subsequent cooling phase) are considered separately. Consequently the total fire exposure is considered to be the sum of two thermal actions, one positive and one negative.

To define the load bearing capacity of the structure under real fire conditions (the third step of calculation) the basic relations of a kinetic concept of critical strain are used, as well as the principle of a linear summation of damages and creep flow $/ 5 /$. The calculation of the load bearing capacity of the structure, based on the static approach, described in /1/

\section{RESULTS AND DISCUSSION}

on the basis of the premises and methods described above, more than 160 combinations of the opening factor of the compartment, the fire load density and the structural characteristics have been computed in order to find the effect of the real fire exposure. The structure chosen is a reinforced concrete ceiing slab.*

Initinal data: the slab width $-1.2 \mathrm{~m}$; the slab thickness $-0.2 \mathrm{~m}$; the thickness of concrete cover of the principal reinforcement $=0.015 ; 0.02 ; 0.025,0.03 \mathrm{~m} ;$ principal reinforcement $0.012 \mathrm{~m}$ in diameter; the cross-section area of the principal reinforcement - $0.000452 \mathrm{~m}$; kinetic characteristics of reinforcement strength $/ 5 / \mathrm{U}_{0}=286 \mathrm{~kJ} / \mathrm{mol}, \gamma=0.095 \mathrm{~kJ} /(\mathrm{mol} \mathrm{MPa})$;

concrete $\rho=2350 \mathrm{~kg} / \mathrm{m}, \mathrm{R}_{5}=11 \mathrm{MPa}$.
Compartment: opening factor $\mathrm{K}_{1}=0.02 ; 0.04 ; 0.06 ; 0.08 ; 0.12 \mathrm{~m} \mathrm{~m}^{1 / 2}$ $/ 2,4,6 /$.

The fire load density in the compartment $q: 150-800 \mathrm{MJ} / \mathrm{m}^{2}$. The bending moment from workloads $\mathrm{M}=50700 \mathrm{Nm}$.

All variants of this task have been computed by 2 methods based on the static and kinetic $/ 5,6 /$ approaches.

When appreciating the critical fire load density in a compartment on the basis of the static approach, the fire load density in a compartment is considered to be critical under design criterion (5), when $\mathrm{T}_{\mathrm{S}}^{\mathrm{Cr}}=492^{\circ} \mathrm{C}$.

When appreciating the value of the critical fire load density in a compartment on the basis of the kinetic approach, the fire load density in a compartment $\mathrm{cr}^{\text {is }}$ considered to be critical under design criterion (4) when $\varepsilon^{\mathrm{cr}}=0.044$.

* work was done with participation of M.A.Abdul Majeed 


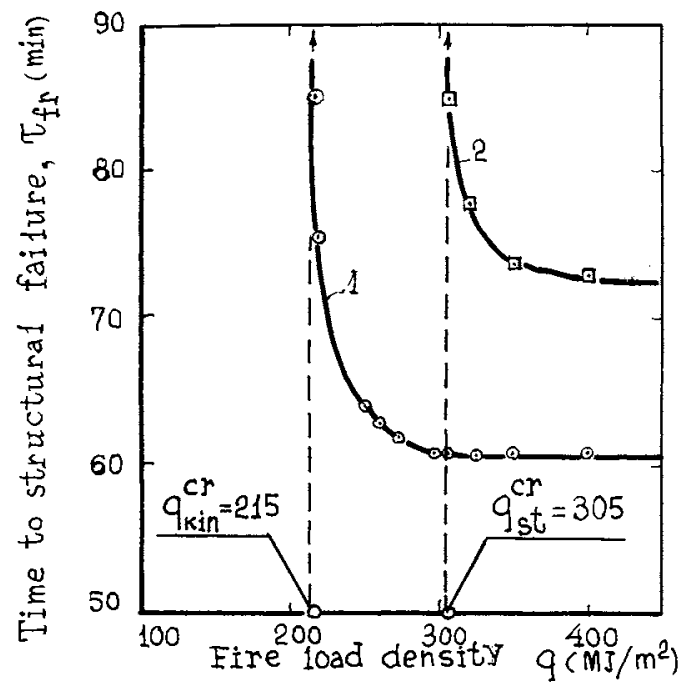

FIGURE 2. Typical diagram of the results from one design series giving the critical fire load density $q$ in $a$ compartment $\left(K_{1}=0.04 \mathrm{~m}^{1 / 2}\right)$, based on a real fire exposure on a reinforced concrete ceiling $\operatorname{slab}(\delta=0.025 \mathrm{~m})$. 1-kinetic approach application; 2-static approach application.

The computed results are illustrated by the following table and figures 2 and 3 .

Figure 2 shows the calculated relationship between the fire load density $q$ and the time to failure for a reinforced concrete slab with a specified concrete cover $=0,025 \mathrm{~m}$ when reposed to a simulated real fire in a specified compartment with the opening factor $0,04 \mathrm{~m}^{\frac{1}{2}} \tau_{f r} \rightarrow \infty$ defines the critical fire load density $q^{c r}$ below which no structural failure will occur. The two curves 1 and 2 relate to calculations based on the kinetic and static approaches, respectively.

Systematically performed calculations according to Figure 2 are summarized in the table, reporting the critical fire load densities according to the kinetic $q_{k i n}^{c r}$ and static aproaches $q_{s}^{c r}$ for diferent combinations of the opening factor of the compartment and the concrete cover of the reinforced concrete ceiling slab.

In all diagrams similar to Fig.2, the values of the critical fire load density in a compartment obtained by the calculation on the basis of the static approach are more than $q$, obtained by the calculation on the basis of the kinetic approach (see Table and Fig.2).

It shows that when solving the static tasks of fire resistance 
the underestimation of the real fire danger takes place since the value of the critical fire load density in a compartment that must provide the safety of all structures under the real fire is overvalued. It occurs because of the initial theoretical premises of static approach under which it is impossible to consider the changing strength and deformation properties of structural materials in the phase of cooling /5/

TABLE

The critical fire load density $\mathrm{q}^{c r}$ in specified compartments determined a real fire exposure on a reinforced concrete slab by kinetic and static approaches

\begin{tabular}{|c|c|c|c|c|c|}
\hline \multirow{2}{*}{$\begin{array}{l}\text { Opening } \\
\text { factor } \\
K \\
\left(m^{1 / 2}\right)\end{array}$} & \multirow{2}{*}{$\begin{array}{l}\text { Thickness } \\
\text { of conc- } \\
\text { rete } \\
\text { cover } \delta(m)\end{array}$} & \multicolumn{2}{|c|}{$q^{c r}\left(M J / m^{2}\right)$} & \multirow{2}{*}{$\begin{array}{l}\Delta q^{c r}= \\
=q_{s t}^{c r}-q_{k i n}^{c r}\end{array}$} & \multirow{2}{*}{$\begin{aligned} \Delta \% & =\frac{\Delta q^{c r}}{q_{\text {kin }}^{c r}} 100 \%\end{aligned}$} \\
\hline & & $q_{k i n}^{c r}$ & $q_{s t}^{c r}$ & & \\
\hline 0.12 & $\begin{array}{l}0.015 \\
0.02 \\
0.025 \\
0.03\end{array}$ & $\begin{array}{l}365 \\
420 \\
475 \\
525\end{array}$ & $\begin{array}{l}435 \\
520 \\
615 \\
710\end{array}$ & $\begin{array}{l}70 \\
100 \\
140 \\
185\end{array}$ & $\begin{array}{l}19.2 \\
23.8 \\
29.5 \\
35.2\end{array}$ \\
\hline 0.08 & $\begin{array}{l}0.015 \\
0.02 \\
0.025 \\
0.03\end{array}$ & $\begin{array}{l}265 \\
305 \\
340 \\
385\end{array}$ & $\begin{array}{l}320 \\
385 \\
455 \\
530\end{array}$ & $\begin{array}{l}55 \\
80 \\
115 \\
140\end{array}$ & $\begin{array}{l}20.7 \\
26.2 \\
33.8 \\
36.4\end{array}$ \\
\hline 0.06 & $\begin{array}{l}0.015 \\
0.02 \\
0.025 \\
0.03\end{array}$ & $\begin{array}{l}215 \\
245 \\
275 \\
305\end{array}$ & $\begin{array}{l}265 \\
320 \\
375 \\
440\end{array}$ & $\begin{array}{l}50 \\
75 \\
100 \\
125\end{array}$ & $\begin{array}{l}23.2 \\
30.6 \\
36.4 \\
41\end{array}$ \\
\hline 0.04 & $\begin{array}{l}0.015 \\
0.02 \\
0.025\end{array}$ & $\begin{array}{l}165 \\
190 \\
215\end{array}$ & $\begin{array}{l}215 \\
255 \\
305\end{array}$ & $\begin{array}{l}50 \\
65 \\
90\end{array}$ & $\begin{array}{l}30.3 \\
34.2 \\
41.8\end{array}$ \\
\hline 0.02 & 0.02 & 115 & 160 & 45 & 39 \\
\hline
\end{tabular}

The use of the kinetic approach for solving this task as well permits to consider all thermal history of the real fire exposure including the cooling phase of structure. During this phase the structures additionally lose the part of their load bearing capacity. That is why, the design values of the critical fire load density obtained on the basis of the kinetic approach are always less than the similar data obtained under the static calculation, that is $q_{k i n}^{c r}<q_{s t}^{c r}$.

To appreciate the possible underestimation value of the real fire danger when caculating the critical fire density in a compartment using the static approach, the computed results were treated by the formula: (see Table)

$\Delta=q_{s t}^{c r}-q_{k i n}^{c r} / q_{k i n}^{c r} 100 \%$

where: $q_{x i n}^{c r}$ - the value of the critical fire load density in a 
compartment obtained by more precise calculation on the basis of the kinetic approach; q $\mathrm{q}_{\text {st }}^{\mathrm{cr}}$ the critical fire load density in a compartment obtained by the static calculation without considering the phase of fire decay.

The Table data are shown in Fig. 3 in the form of dependence $\Delta\left(\delta, K_{1}\right)$.

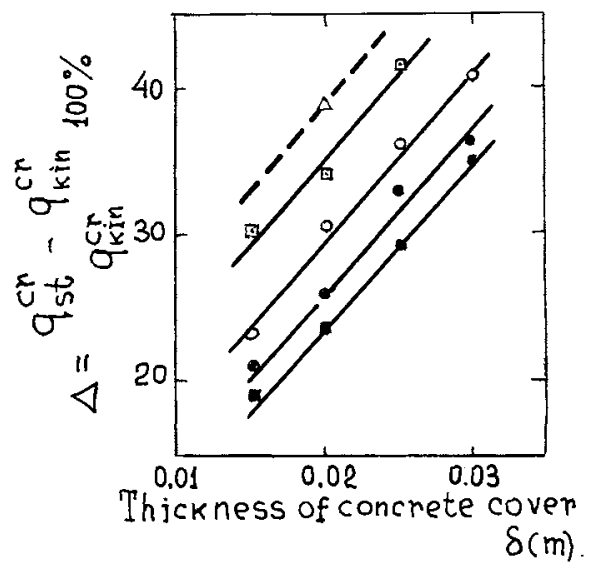

FIGURE 3. Dependence of possible underestimate $\Delta \%$ of value of the critical fire load density $\mathrm{q}^{\mathrm{cr}}$ in compartments on the opening factor $K_{1}$ and the thickness of concrete cover $\delta$ on the effect of the real fire exposure on the reinforced concrete slab by the static approach application.

$1-K_{1}=0.02 ; 2-0.04 ; 3-0.06 ; 4-0.08 ; 5-0.12\left(\mathrm{~m}^{1 / 2}\right)$.

The diagram in Fig.3 shows that the level of possible underestimation of the real fire danger under static calculation of the critical fire load density in a compartment may constitute more than $38-40 \%$.

\section{CONCLUSIONS}

Thus, the use of the kinetic approach to solve the various problems of fire safety connected with the structural behaviour under the real fire makes it possible to consider the special features of the real fire exposure more precisely and completely than under static calculations and obtain either social and economical effect. The kinetic approach can also be used under the calculations of the critical fire load density in a compartment.

\section{REFERENCES}

1. Astapenko, V.M., Koshmarov, Y.A., Molchadski, I.S. and Shewliakov, A.N. Thermo-gasdynamics of fire in compartment, ed.Y.A.Koshmarov. Strojizdat, Moscow,1988, p.p.258-263. 
2. Pettersson, O., Magnusson, S-E, and Thor, J., "Fire engineering design of steel structures", Publication 50, Swedish Institute of Steel Construction, Stockholm,1976.

3. Harmathy, T.Z.,"Properties of Building materials:Bases for fire safety design", Design of Structures against Fire,ed. R.D.Anchor, H.L.Malhotra and J.A.Purkiss.Elsevier Applied Science, London, 1986, 87-104.

4. Petterson, 0., "Practical need of scientific material models for structural fire design, general review", Fire Safety Journal, 13 (1988) 1-8.

5. Roitman, V.M.,"Consideretions of Real Fire Conditions while Calculating the Fire Resistance of Building structures on the Basis of the Kinetic Approach", Fire Safety Journal, 16 (1990) 433-442.

6. Roitman, V.M., Demekhin, V.N. and Abdul Majeed, M.A., "A Simplified Predication Method of Real Fire Exposure as a Basis for an Analytical Structural Fire Design", Fire Safety Science, Proceedings of the Third International symposium, p.751-759,1991. 
